\title{
Isotopic composition of xenon in petroleum from the Shell Bullwinkle Field
}

\author{
J NUZZO*, M HYMAN and M W Rowe** \\ Department of Chemistry, Texas AESM University, College Station, TX 77843. \\ * Present address: Barrens Consulting Co., 273 Pepe's Farm Road, Milford, CT 06470. \\ **email: MWRowe@tamu.edu \\ M N RAO $\ddagger$ and R L PALMA \\ Department of Physics, Sam Houston State University, Huntsville, TX 77341. \\ ${ }^{\ddagger}$ Present address: SN4, NASA-JSC, Houston, TX 77858 .
}

\section{J WESTRICH}

Shell Development Corporation, P.O. Box 481, Houston, Texas 77001.

We have measured the abundance and isotopic composition of xenon in petroleum samples from the Shell Bullwinkle Field off the coast of Louisiana. We used an oxidation and purification procedure designed to insure complete extraction and clean up of xenon from the petroleum.

The xenon isotopic composition was found to be similar to the atmospheric value for one petroleum sample. While the results of the second sample suggest possible enrichment of the heavier isotopes, the errors associated with these excesses preclude a definitive statement to that effect. No monoisotopic enrichment in ${ }^{129} \mathrm{Xe}$ was detected in either sample, the presence of which might have allowed us to deduce the petroleum age. Our results represent only the second xenon measurement from petroleum, and the concentrations are within the range of values published in the earlier report.

\section{Introduction}

Noble gas isotopes as conservative tracers are increasingly applied to a variety of terrestrial systems. Elemental abundances and isotopic compositions of noble gases have been determined in natural gas (Zartman et al 1961; Hennecke and Manuel 1975; Murthy 1992; Hiyagon and Kennedy 1992; Xu et al 1995), and in ground water and geothermal systems (Mazor et al 1983; Andrews et al 1985; Torgerson and Clark 1985; Tolstikhin et al 1996). Rare gases have been used to characterize the degree of interaction between natural gas, hydrocarbon assemblages and associated ground water and to quantify the contribu- tion of mantle- and crustal-derived rare gases to hydrocarbon accumulation (Ballentine et al 1991, 1996; Elliot et al 1993).

Bosch and Mazor (1988) used noble gas measurements in natural gas samples to test a proposed model for equilibrium distribution of atmospheric noble gases between natural gas associated with water and oil and between natural gas associated with water alone. They found that for both cases (association with and without oil), relative abundances of the heavier noble gases, $\mathrm{Kr}$, and especially Xe, were enriched compared to atmosphere by factors ranging from two to ten. Enrichment was greatest for natural gas samples associated with petroleum. The enrichment of the

Keywords. Xenon; petroleum; isotopic composition; mass spectrometry. 
heavier noble gases is believed to be due to the initial enrichment of these gases in the aqueous phase and (or) petroleum, followed by desorption to natural gas. By fitting their results and other published data to their model, they concluded that atmospheric noble gases found in natural gases were initially contained in an air-saturated water phase and subsequently distributed between this water phase and the natural gas phase. Kharaka and Specht (1988) showed that under reservoir conditions, solubilities of noble gases in petroleum are higher than in subsurface waters by factors ranging from 2 to 300 , with the solubility enrichment factor being greatest for the heavier noble gases.

While the utility of noble gas measurements in ground waters and natural gas samples has been well established, it is only recently that detailed noble gas measurements were reported from petroleum (Pinti and Marty 1995; Ballentine et al 1996). Ballentine et al (1996) in their comprehensive study of noble gas isotope systematics in a liquid hydrocarbon reservoir (using $\mathrm{He}, \mathrm{Ne}$ and Ar) showed that noble gas partitioning between gas, water and oil phases is a function of solubility, phase volume and temperature in this system and for calculating the noble gas inventory of an oil reservoir, carefully determined values for these parameters need to be used. Pinti and Marty (1995) carried out similar studies of oil reservoirs using He, $\mathrm{Ne}, \mathrm{Ar}, \mathrm{Kr}$ and $\mathrm{Xe}$ isotopes. In their method the petroleum sample is drained into an evacuated ( $\sim 10^{-10}$ torr $)$ extraction vessel where it is magnetically stirred, and a small gas fraction isolated, cleaned and subsequently analyzed in a noble gas mass spectrometer. In contrast, we designed and built an off-line system to extract xenon by complete oxidation of petroleum. This was to ensure purification of the evolved gases, eliminating possible contamination of the noble gas mass spectrometer. The purpose of our study is to explore the feasibility of detecting ${ }^{129} \mathrm{Xe}$ excesses in petroleum due to decay of cosmogenic ${ }^{129} \mathrm{I}$ produced in the atmosphere, thereby providing under favorable conditions a potential geochronological technique for estimating ages of petroleum reservoirs.

\section{Analytical procedures}

Two petroleum samples from their offshore Bullwinkle Field, Louisiana, were provided by the Shell Exploration and Production Technology Corporation, Houston, Texas: NG-G-548A from well A-2, and NG-G$550 \mathrm{~A}$ from well A-32. The location of A-2 is $27.88311^{\circ} \mathrm{N}, 90.90153^{\circ} \mathrm{W}$, with production depth interval $13,657-13,704$ feet; and A-32 is at $27.88293^{\circ} \mathrm{N}$, $90.90155^{\circ} \mathrm{W}$, with production depth interval $12,858-$ 12,970 feet. This field consists of approximately 40 $50 \%$ bacterial gas with the remainder of the gas and oil derived from a Middle Cretaceous rock dated at about $100 \times 10^{6}$ years. Samples were taken directly from the head of a gas-liquid separator into high pressure stainless steel containers by Shell Exploration and Production Technology personnel. The filled cylinders contained a mixture of petroleum, natural gas, and a small amount of water.

To minimize exposure of the petroleum samples to the atmosphere, several precautions were taken during retrieval of petroleum from the high pressure stainless steel cylinder. A stainless steel collection finger was connected directly to the closed cylinder valve, the collection finger was evacuated and then filled with natural gas from the cylinder. This process was repeated several times to further purge the collection finger of any atmospheric component initially present in the finger. Petroleum was then allowed to drain under gravity into the collection finger.

With the collection finger closed to the cylinder, excess pressure within the collection finger was vented under a nitrogen atmosphere. While still under nitrogen atmosphere, the collection finger was removed from the cylinder and the petroleum was quickly transferred to $1 \mathrm{ml}$ glass vials. The vials were filled completely so there were no gas pockets present when sealed with a gas-tight Teflon-lined screw cap. The samples were wrapped with parafilm and stored in a freezer until their analysis. Storage time was kept below 48 hours.

Xenon was extracted by completely oxidizing the petroleum sample in an off-line ultra-high-vacuum system shown schematically in figure 1 . This allowed xenon to be extracted and purified before introduction into the mass spectrometer for analysis. A stainless steel reaction chamber $(45 \mathrm{~cm}$ long with an inner diameter of $3.8 \mathrm{~cm}$ and tapered at both ends) was constructed for oxidizing petroleum. It was loosely packed with quartz wool to enhance oxidation by providing more surface area and/or by impeding the escape of volatile organic fractions from the reaction tube before they were completely oxidized.

Petroleum was deposited at the end of the reaction chamber with a glass insertion tube $(8 \mathrm{~cm}$ long with an inner diameter of $3 \mathrm{~mm}$ ) fitted with a gas-tight Teflon plunger. To minimize exposure to the atmosphere, petroleum was transferred from the storage vial to the insertion tube under a nitrogen atmosphere. The filled insertion tube was quickly weighed under nitrogen atmosphere, then reweighed after the petroleum was transferred, yielding the weight of the petroleum transferred into the extraction system.

While the petroleum was being introduced, the reaction chamber was isolated from the remainder of the system. Ultra-high-purity $(99.999 \%)$ oxygen was flowed into the chamber, producing a pressure slightly greater than one atmosphere. With this positive oxygen pressure maintained, a blank flange at the end of the reaction chamber was removed and the 


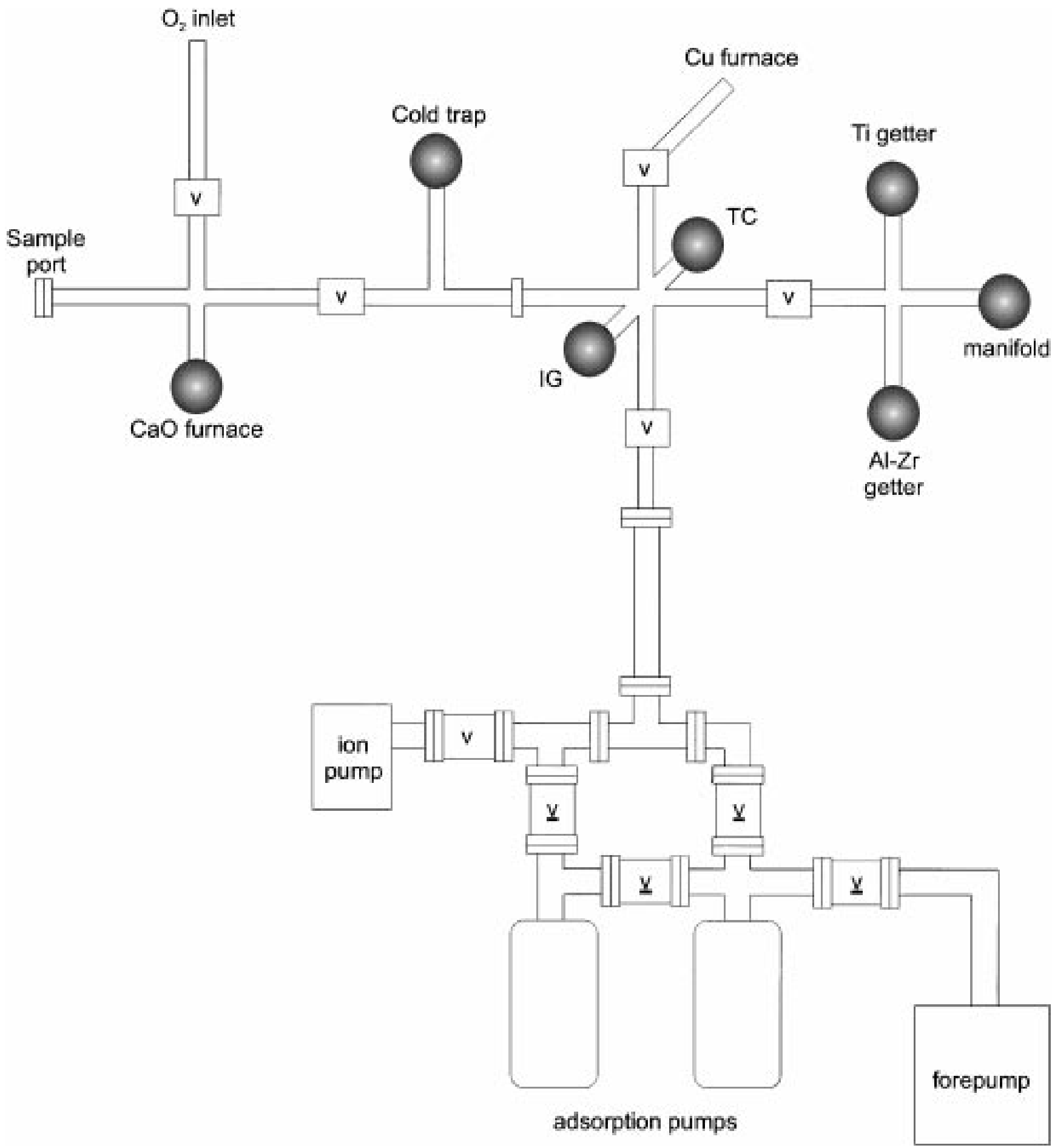

Figure 1. Schematic diagram of the noble gas extraction system. The abbreviations TC and IG represent the thermocouple and ion gauge, respectively. All-metal bakeable valves are designated with v. Non-bakeable valves are abbreviated with $\underline{v}$. Other components are labeled on the diagram.

tube containing the petroleum sample inserted. Once the sample was deposited and the tube removed, the blank flange was replaced. The entire insertion and transfer took approximately 25 seconds.

With the sample deposited at the end of the reaction chamber, and an oxygen pressure of $\sim 1000$ torr, the entire reaction column was heated in stages using two independent resistance heaters. In stage one, the half of the reaction tube opposite the sample introduction end was heated to $800^{\circ} \mathrm{C}$. Once this section of the reaction tube reached temperature, the other half of the reaction tube was heated to $800^{\circ} \mathrm{C}$. We earlier determined that oxidizing the petroleum in just one heating stage caused the petroleum components 
to volatilize during heating, only to deposit on cooler surfaces of the system, leaving behind an oily film. In the two-stage heating procedure, volatile components released during heating of the petroleum are oxidized upon entering the hotter zone of the second heater. Xenon extraction was found to be nearly complete as the third step yielded only small amounts of xenon.

Three clean-up stages were employed to separate xenon from copious amounts of unwanted gases, primarily $\mathrm{CO}_{2}$ and $\mathrm{H}_{2} \mathrm{O}$, as well as possible hydrocarbons. In the first stage of the clean-up, the bulk $\mathrm{CO}_{2}$ and $\mathrm{H}_{2} \mathrm{O}$ formed from the oxidation of the petroleum was removed with a $\mathrm{CaO}$ getter, and unreacted $\mathrm{O}_{2}$ was removed using a $\mathrm{Cu}$ getter. In the second stage of the clean-up, both a bulk $\mathrm{Ti} / \mathrm{Zr}$ getter and a $\mathrm{Zr} / \mathrm{Al}$ (SORBAC) getter were used to remove any reactive gases remaining from the first stage of the clean-up. The third stage of the clean-up involved preferential adsorption of xenon onto activated charcoal cooled by $\mathrm{CHCl}_{3}$ and liquid nitrogen slurry $\left(-66^{\circ} \mathrm{C}\right)$ while pumping off unadsorbed gases. The second and third stages of the clean-up were repeated alternately for several cycles to further clean the xenon.

The purified xenon samples were removed from the extraction system by collection onto an activated charcoal finger cooled to $-66^{\circ} \mathrm{C}$; at this temperature only xenon was completely adsorbed. The collection finger was sealed and subsequently attached to the mass spectrometer system. When the sample gas was released from the cold finger for analysis, the evolved gas was further cleaned in the mass spectrometer sample line by bulk $\mathrm{Ti} / \mathrm{Zr}$ and $\mathrm{Zr} / \mathrm{Al}$ getters. A Nuclide, $15 \mathrm{~cm}$ radius, $60^{\circ}$ magnetic sector, noble gas mass spectrometer operated in the static mode was employed for elemental and isotopic analysis (Reynolds 1956).

\section{Results}

Procedural blanks were measured to determine the background level of xenon. All conditions were the same as for the later petroleum processing with the exception that no petroleum was added to the system. Signal intensities of ${ }^{132} \mathrm{Xe}$ for a procedural blank and the two petroleum samples, NG-G-548A (and its duplicate, NG-G-548A-1) and NG-G-550A, are given

Table 1. ${ }^{132}$ Xe and total xenon concentrations. Uncertainties in all values are $<10 \%$.

\begin{tabular}{lcc}
\hline Sample & $\begin{array}{c}{ }^{132} \mathrm{Xe} \\
\left(10^{-10} \mathrm{~cm}^{3} \mathrm{STP}\right)\end{array}$ & $\begin{array}{c}\text { Xenon }\left(10^{-8} \mathrm{~cm}^{3}\right. \\
\text { STP } / \mathrm{g} \text { petroleum })\end{array}$ \\
\hline NG-G-548A & 4.05 & 3.35 \\
NG-G-548A-1 & 5.90 & 2.93 \\
NG-G-550A & 5.38 & 2.67 \\
Procedural blank & 0.052 & \\
\hline
\end{tabular}

in table 1 . The procedural blank xenon intensity was approximately two orders of magnitude lower than the petroleum samples. While the xenon concentrations listed in table 1 do not take into consideration possible xenon losses and additions prior to sampling, the values fall within the range of xenon from petroleum measured by Pinty and Marty (1995) of 1.7 to $18.5 \times 10^{-8} \mathrm{~cm}^{3} \mathrm{STP} / \mathrm{g}$. As petroleum is a heterogeneous liquid comprised of oil, brine and gas, it is necessary to know the gas/water and oil/water ratios for a given sample. Unfortunately, these data were not available to us from the supplier of the petroleum samples.

The blank and mass discrimination corrected xenon isotopic compositions for the petroleum samples are given in table 2. For comparison, average values of an air xenon spike, measured on four separate occasions, are also given in this table. The only other isotopic compositions measured for xenon from petroleum are reported by Pinti and Marty (1995), as being "identical to those of air."

\section{Discussion}

The measured ${ }^{129} \mathrm{Xe}$ contents here are essentially mixtures of atmospheric plus fissiogenic and cosmogenic components and under favorable conditions, atmospheric $\left({ }^{130} \mathrm{Xe}\right.$ or ${ }^{132} \mathrm{Xe}$ based) and fissiogenic ( ${ }^{136} \mathrm{Xe}$ based) contributions can be subtracted to yield, the content of the cosmogenic component. However large errors associated with the resultant values are unavoidable because of cumulative subtraction procedure. Several points can be made from the isotopic compositions listed in table 2 . The isotopic compositions of sample NG-G-548A and its duplicate, NG-G$548 \mathrm{~A}-1$, are indistinguishable from one another and the air xenon spikes within experimental uncertainty. However, for sample NG-G-550A, light isotopic ratios ${ }^{124-130} \mathrm{Xe} /{ }^{132} \mathrm{Xe}$ fall distinctly below those measured for air xenon, suggesting a heavy isotope-rich component in this sample. The two lightest, low abundance isotopes, ${ }^{124} \mathrm{Xe}$ and ${ }^{126} \mathrm{Xe}$, are found in lower concentrations than those determined in the blank. Although caution must be employed because of somewhat larger uncertainties in isotopic ratios for sample NG-G$550 \mathrm{~A}$, we examined the possibility of heavy xenon isotopic excesses by renormalizing all data for this sample to ${ }^{130} \mathrm{Xe}$, which is a fission shielded isotope and thus useful for this purpose. These ${ }^{130} \mathrm{Xe}$ normalized isotopic ratios were subtracted from air xenon values, and the resulting excesses compared to the compositions resulting from ${ }^{238} \mathrm{U}$ spontaneous fission and ${ }^{238} \mathrm{U}$ and ${ }^{235} \mathrm{U}$ neutron-induced fission (Ragettli et al 1994) by plotting $\Delta_{i} \Delta_{136}$, where $\Delta_{i}=\left({ }^{i} \mathrm{Xe} /{ }^{130} \mathrm{Xe}\right)$ sample $^{-}$ $\left({ }^{i} \mathrm{Xe} /{ }^{130} \mathrm{Xe}\right)_{\text {air }}$ and $i$ is a mass number of xenon (figure 2). Error propagation introduces large uncertainties when subtracting data of similar values, 
Table 2. Xenon isotopic compositions.

\begin{tabular}{|c|c|c|c|c|c|c|c|c|}
\hline Sample NG-G- & $\frac{{ }^{124} \mathrm{Xe}}{{ }^{132} \mathrm{Xe}}$ & $\frac{126 \mathrm{Xe}}{{ }^{132} \mathrm{Xe}}$ & $\frac{128 \mathrm{Xe}}{\frac{132 \mathrm{Xe}}{{ }^{2}}}$ & $\frac{}{\frac{129}{132} \mathrm{Xe}}$ & $\frac{130 \mathrm{Xe}}{{ }^{132} \mathrm{Xe}}$ & $\frac{{ }^{131} \mathrm{Xe}}{{ }^{132} \mathrm{Xe}}$ & $\frac{{ }^{134} \mathrm{Xe}}{{ }^{132} \mathrm{Xe}}$ & $\frac{136 \mathrm{Xe}}{{ }^{132} \mathrm{Xe}}$ \\
\hline $548 \mathrm{~A}$ & $\begin{array}{r}0.0031 \\
\pm 0.0008\end{array}$ & $\begin{array}{r}0.0029 \\
\pm 0.0008\end{array}$ & $\begin{array}{r}0.0721 \\
\pm 0.0009\end{array}$ & $\begin{array}{r}0.9905 \\
\pm 0.0079\end{array}$ & $\begin{array}{r}0.1512 \\
\pm 0.0012\end{array}$ & $\begin{array}{r}0.7916 \\
\pm 0.0054\end{array}$ & $\begin{array}{r}0.3908 \\
\pm 0.0018\end{array}$ & $\begin{array}{r}0.3273 \\
\pm 0.0021\end{array}$ \\
\hline $548 \mathrm{~A}-1$ & $\begin{array}{r}0.0035 \\
\pm 0.0002\end{array}$ & $\begin{array}{r}0.0033 \\
\pm 0.0002\end{array}$ & $\begin{array}{r}0.0712 \\
\pm 0.0006\end{array}$ & $\begin{array}{r}0.9806 \\
\pm 0.0059\end{array}$ & $\begin{array}{r}0.1510 \\
\pm 0.0011\end{array}$ & $\begin{array}{r}0.7891 \\
\pm 0.0049\end{array}$ & $\begin{array}{r}0.3930 \\
\pm 0.0024\end{array}$ & $\begin{array}{r}0.3342 \\
\pm 0.0019\end{array}$ \\
\hline $550 \mathrm{~A}$ & * & * & $\begin{array}{r}0.0676 \\
\pm 0.0059\end{array}$ & $\begin{array}{r}0.974 \\
\pm 0.014\end{array}$ & $\begin{array}{r}0.1471 \\
\pm 0.0054\end{array}$ & $\begin{array}{r}0.7886 \\
\pm 0.0078\end{array}$ & $\begin{array}{r}0.3907 \\
\pm 0.0048\end{array}$ & $\begin{array}{r}0.3329 \\
\pm 0.0060\end{array}$ \\
\hline Air spike & $\begin{array}{r}0.0035 \\
\pm 0.0003\end{array}$ & $\begin{array}{r}0.0033 \\
\pm 0.0003\end{array}$ & $\begin{array}{r}0.0713 \\
\pm 0.0017\end{array}$ & $\begin{array}{r}0.9842 \\
\pm 0.0064\end{array}$ & $\begin{array}{r}0.1523 \\
\pm 0.0008\end{array}$ & $\begin{array}{r}0.7884 \\
\pm 0.0059\end{array}$ & $\begin{array}{r}0.3899 \\
\pm 0.0024\end{array}$ & $\begin{array}{r}0.3318 \\
\pm 0.0026\end{array}$ \\
\hline
\end{tabular}

*Below blank levels.

which is commonly encountered in xenon data analyses.

In figure 2 , if $\Delta_{134} / \Delta_{136}$ for sample NG-G-550A is considered to represent fission xenon extracted from this sample, there is a suggestion of a ${ }^{235} \mathrm{U}$ and ${ }^{238} \mathrm{U}$ neutron-induced fission component, although the uncertainties associated with these data do not rule out a ${ }^{238} \mathrm{U}$ spontaneous fission contribution. However, measured excesses at ${ }^{131} \mathrm{Xe}$ and ${ }^{132} \mathrm{Xe}$ are greater than expected from any fission component, indicating possible contributions from ${ }^{130} \mathrm{Te}(n, \gamma){ }^{131} \mathrm{Xe},{ }^{130} \mathrm{Ba}$ $(n, \gamma){ }^{131} \mathrm{Xe}$ and ${ }^{133} \mathrm{Cs}(n, 2 n){ }^{132} \mathrm{Xe}$ reactions in the subsurface rock environment through which the petroleum migrated over the last several million years. In

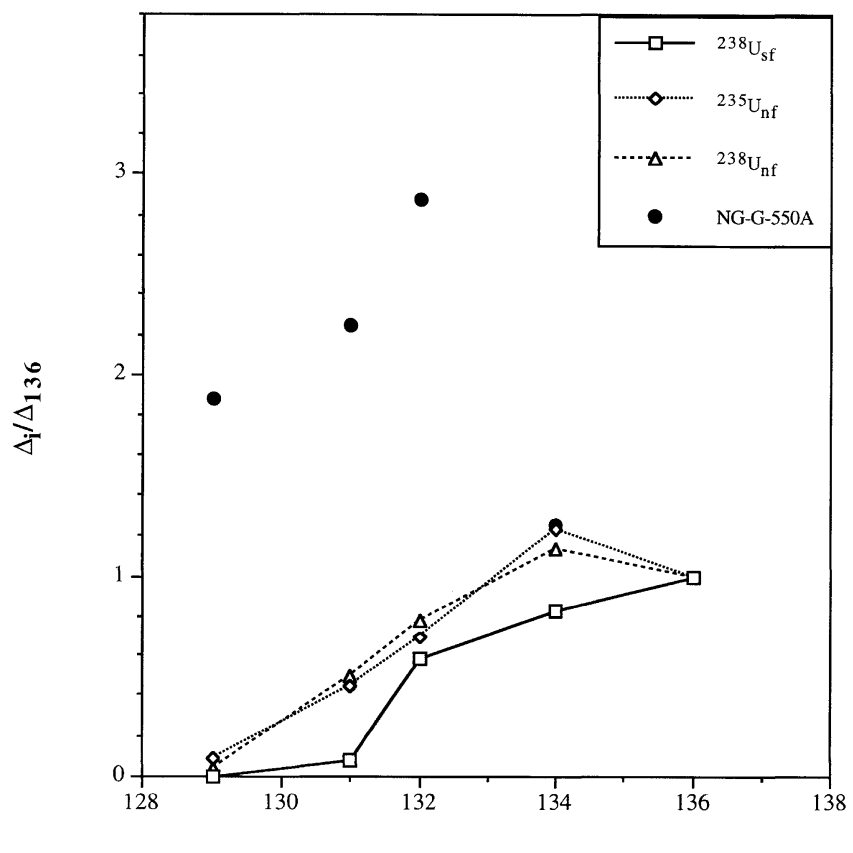

Mass Number

Figure 2. Petroleum sample NG-G-550A shows an enrichment in ${ }^{129} \mathrm{Xe},{ }^{131} \mathrm{Xe}$ and ${ }^{132} \mathrm{Xe}$ relative to the ${ }^{238} \mathrm{U}$ spontaneous fission composition $\left({ }^{238} \mathrm{U}_{\mathrm{sf}}\right)$, the ${ }^{235} \mathrm{U}$ neutron-induced fission composition $\left({ }^{235} \mathrm{U}_{\mathrm{nf}}\right)$ and the ${ }^{238} \mathrm{U}$ neutron-induced fission composition $\left({ }^{238} \mathrm{U}_{\mathrm{nf}}\right)$. Error bars are omitted for figure clarity, and $\Delta_{i}=\left({ }^{i} \mathrm{Xe} /{ }^{130} \mathrm{Xe}\right)_{\text {sample }}-\left({ }^{i} \mathrm{Xe} /{ }^{130} \mathrm{Xe}\right)_{\text {air }} \cdot\left[\Delta_{129}=0.15\right.$ $( \pm 0.26) ; \Delta_{131}=0.18( \pm 0.20) ; \Delta_{132}=0.23( \pm 0.25) ; \Delta_{134}=0.10$ $\left.( \pm 0.10) ; \Delta_{136}=0.08( \pm 0.09)\right]$. particular, the large $\Delta_{129} / \Delta_{136}$ suggests the possibility of neutron induced reactions, since a ${ }^{129} \mathrm{Xe}$ excess could be produced from ${ }^{128} \mathrm{Te}(n, \gamma){ }^{129} \mathrm{Xe}$ and ${ }^{130} \mathrm{Te}$ $(n, 2 n)^{129} \mathrm{Xe}$. Even though tellurium is not a common element in the earth's crust, its role in ${ }^{129} \mathrm{Xe}$ subsurface production is found to be important (Bennett and Manuel 1970; Murthy 1992). Thermal and epithermal/fast neutrons are produced in nature from ${ }^{238} \mathrm{U}$ fission. The $n, \gamma$ reactions on ${ }^{128} \mathrm{Te}$ and ${ }^{130} \mathrm{Te}$ result in ${ }^{129} \mathrm{Xe} /{ }^{131} \mathrm{Xe}$ production ratios of 0.7 for thermal neutrons and 4.0 for epithermal neutrons (Brown and Berman 1973; Murthy 1992). The observed ${ }^{129} \mathrm{Xe} /{ }^{131} \mathrm{Xe}$ excess of 0.8 for petroleum sample NG-G-550A is consistent within our experimental uncertainties with the value of 0.7 for thermal neutrons. If this explanation is correct, it may be difficult to resolve any excess ${ }^{129} \mathrm{Xe}$ from decay of radioactive ${ }^{129}$ I from neutron-produced ${ }^{129} \mathrm{Xe}$. When xenon isotopic data with smaller uncertainties are obtained, it will be possible to estimate the neutron-induced contributions to ${ }^{129-132} \mathrm{Xe}$ from average abundances of $\mathrm{Te}, \mathrm{Ba}$ and $\mathrm{Cs}$ in subsurface rocks associated with petroleum.

Differences in xenon concentrations observed between the two petroleum samples may be indicative of a varying degree of interaction with either the atmosphere and/or atmospheric sources of xenon, such as air-saturated ground waters. The smaller deviation from atmospheric isotopic ratios for samples NG-G-548A and 548A-1, compared to NG-G-550A, would suggest a greater interaction with one of these sources, and would be consistent with the concentrations of xenon found in these samples (table 1).

\section{Conclusions}

A xenon gas extraction and purification system was constructed and utilized to isolate the xenon from two petroleum samples. Xenon compositions were subsequently determined by high sensitivity noble gas mass spectrometry. For sample NG-G-548A and its duplicate NG-G-548A-1, the isotopic composition is indistinguishable from that of the atmosphere, as was found 
for the only other measurements of xenon extracted from petroleum (Pinti and Marty 1995). However, in sample NG-G-550A, the isotopic composition of the heavy xenon isotopes, ${ }^{129-134} \mathrm{Xe}$, showed tentative evidence of enrichment compared to atmospheric ratios. Nuclear processes which might have contributed to this putative heavy isotope enriched component cannot be firmly established given the uncertainties in the data. In neither sample was there evidence of a monoisotopic enrichment of ${ }^{129} \mathrm{Xe}$, relative to the atmospheric value, from the decay of ${ }^{129} \mathrm{I}$. However, the subtle suggestion of a heavy xenon isotope enrichment in sample NG-G-550A leaves the possibility open that future work on additional samples may yield definitive isotopic anomalies which may allow a geochronological dating technique for petroleum to be established.

\section{Acknowledgements}

We are grateful for support from the Robert A. Welch Foundation grants X-1256 and A-1235, and the Texas Advanced Technology Program grant 003606-012, and the Donors of the Petroleum Research Fund administered by the American Chemical Society grant ACS-PRF 20252-AC8. We thank Mr. A Killi of Shell Exploration and Production Technology Corporation, Houston, for petroleum sample collection. We also thank C Ballentine and D L Pinti for their valuable comments on this work.

\section{List of Symbols}

1. $\Delta_{i}=\left({ }^{i} \mathrm{Xe} /{ }^{130} \mathrm{Xe}\right)_{\text {sample }}-\left({ }^{i} \mathrm{Xe} /{ }^{130} \mathrm{Xe}\right)$ air and $i$ is a mass number of xenon.

2. $n$ is the symbol for neutron.

3. $\gamma$ is the symbol for gamma ray emission.

4. $\left.{ }^{130} \mathrm{Te}(n, \gamma)\right)^{131} \mathrm{Xe}$ represents the nuclear reaction in which ${ }^{130}$ Te captures a neutron and emits a gamma ray, producing ${ }^{131} \mathrm{Xe}$.

5. ${ }^{130} \mathrm{Ba}(n, \gamma){ }^{131} \mathrm{Xe}$ represents the nuclear reaction in which ${ }^{130} \mathrm{Ba}$ captures a neutron and emits a gamma ray, producing ${ }^{131} \mathrm{Xe}$.

6. ${ }^{133} \mathrm{Cs}(n, 2 n)^{132} \mathrm{Xe}$ represents the nuclear reaction in which ${ }^{133} \mathrm{Cs}$ captures one neutron and emits two neutrons, producing ${ }^{132} \mathrm{Xe}$.

7. ${ }^{128} \mathrm{Te}(n, \gamma){ }^{129} \mathrm{Xe}$ represents the nuclear reaction in which ${ }^{128}$ Te captures a neutron and emits a gamma ray, producing ${ }^{129} \mathrm{Xe}$.

8. ${ }^{130} \mathrm{Te}(n, 2 n)^{129} \mathrm{Xe}$ represents the nuclear reaction in which ${ }^{130}$ Te captures one neutron and emits two neutrons, producing ${ }^{129} \mathrm{Xe}$.

\section{References}

Andrews J N, Goldbrunner J E, Darling W G, Hooker P J, Wilson G B, Youngman M J, Eichinger L, Rauert W and Stichler W 1985 A radiochemical, hydrochemical and dissolved gas study of groundwaters in the Molasse basin of Upper Austria; Earth Planet. Sci. Lett. 73 317-332

Ballentine C J, O'Nions R K, Oxburgh E R, Horvath F and Deak J 1991 Rare gas constraints on hydrocarbon accumulation, crustal degassing and groundwater flow in the Pannonian Basin; Earth Planet. Sci. Lett. 105 229-246

Ballentine C J, O'Nions R K and Coleman M L 1996 A magnus opus: helium, neon and argon isotopes in a North Sea oilfield; Geochim Cosmochim Acta 60 831-849

Bennett G A and Manuel O K 1970 Xenon in natural gases; Geochim. Cosmochim. Acta. 34 593-610

Bosch A and Mazor E 1988 Natural gas association with water and oil as depicted by atmospheric noble gases: case studies from the southeastern Mediterranean Coastal Plain; Earth Planet. Sci. Lett. 87 338-346

Browne J C and Berman B L 1973 Neutron capture crosssections for ${ }^{128} \mathrm{Te}$ and ${ }^{130} \mathrm{Te}$ and the xenon anomaly in old tellurium ores; Phys. Rev. C 8 2405-2411

Elliot T, Ballentine C J, O'Nions R K and Ricchiuto T 1993 Carbon, helium, neon and argon isotopes in a Po Basin natural gas field; Chem. Geol. 106 429-440

Hennecke E W and Manuel O K 1975 Noble gases in $\mathrm{CO}_{2}$ well gas, Harding County, New Mexico; Earth Planet. Sci. Lett. 27 346-355

Hiyagon H and Kennedy B M 1992 Noble gases in $\mathrm{CH}_{4}$-rich gas fields, Alberta, Canada; Geochim. Cosmochim. Acta $\mathbf{5 6}$ $1569-1589$

Kharaka Y K and Specht D J 1988 The solubility of noble gases in crude oil at $25-100^{\circ} \mathrm{C}$; Appl. Geochem. 3 137-144

Mazor E, Van Everdingen R D and Krouse H R 1983 Noble-gas evidence for geothermal activity in a karstic terrain: Rocky Mountains, Canada; Geochim. Cosmochim. Acta 36 11111115

Murthy S V S 1992 Noble gases and nitrogen in natural gases from Gujarat, India; Chem. Geol. 94 229-240

Pinti D L and Marty B 1995 Noble gases in crude oils from the Paris Basis, France: Implications for the origin of fluids and constraints on oil-water-gas interactions; Geochim. Cosmochim. Acta 59 3389-3404

Ragettli R A, Hebeda E H, Signer P and Wieler R 1994 Uranium-xenon chronology: Precise determination of $\lambda_{\mathrm{sf}}$, ${ }^{136} \mathrm{y}_{\mathrm{sf}}$ for spontaneous fission of ${ }^{238} \mathrm{U}$; Earth Planet. Sci. Lett. $128653-670$

Reynolds J H 1956 High sensitivity mass spectrometer for noble gas analysis; Rev. Sci. Instrum. 69 928-934

Tolstikhin I, Lehmann B E, Loosli H H and Gautschi A 1996 Helium and argon isotopes in rocks, minerals and related groundwaters: A case study in northern Switzerland; Geochim. Cosmochim. Acta 60 1497-1514

Torgersen T and Clarke W B 1985 Helium accumulations in groundwater, I: An evaluation of sources and the continental flux of crustal ${ }^{4} \mathrm{He}$ in the Great Artesian Basin, Australia; Geochim. Cosmochim. Acta 49 1211-1218

Xu S, Nakai S, Wakita H and Wang X 1995 Mantle-derived noble gases in natural gases from Songliao Basin, China; Geochim. Cosmochim. Acta 59 4675-4683

Zartman R E, Wasserburg G J and Reynolds J H 1961 Helium, argon and carbon in some natural gases; J. Geophys. Res. 66, 277-306 